\title{
Morphometric Analysis of Coronoid Process of Mandible by CT in the Malaysian Population: An Important Step for Determination of Sex
}

\author{
Aspalilah Alias ${ }^{1,2}$, Abdel Nasser Mohamad Ibrahim ${ }^{2,3}$, Siti Noorain Abu Bakar ${ }^{2}$, Faezah Rokhani ${ }^{1}$, \\ Mohamed Swarhib Shafie ${ }^{2}$, Faridah Mohd Nor ${ }^{2 *}$ \\ ${ }^{1}$ Faculty of Dentistry, Universiti Sains Islam Malaysia, Kuala Lumpur, Malaysia \\ ${ }^{2}$ Forensic Unit, Department of Pathology, Universiti Kebangsaan Malaysia Medical Centre, Kuala Lumpur, \\ Malaysia \\ ${ }^{3}$ Department of Forensic Medicine and Clinical Toxicology, Faculty of Medicine, Al Azhar University, Cairo, \\ Egypt \\ *Corresponding author: Faridah Mohd Nor, Department of Pathology, Universiti Kebangsaan Ma- \\ laysia Medical Centre, Jalan Yaacob Latif, Bandar Tun Razak, Cheras, 56000 Kuala Lumpur, Malaysia, \\ Tel: +60391455368; E-mail: mnfaridah@gmail.com
}

Received: 28 June, 2018; Accepted: 31 July, 2018; Published: 18 August, 2018

\section{Abstract}

Introduction: Sex determination is vital for developing biological profile in skeletonized remains. Estimation of age, ancestry, and stature are dependent on sex determination. Various parts of cranial and postcranial elements were studied for sex dimorphism in the literature. It is shown that the skeletal morphology in different sex was more pronounced in the adults than in the pre-pubertal period. Objective: The aim of this study was to determine sex in Malaysian adults by morphometric analysis of CT-scanned mandibles. Materials and Methods: The study was performed on 447 slices of scanned mandibles (894 different sides) in 244 males and 203 females. They comprised Malays (150), Chinese (137) and Indian (160) subjects within 18 to 87 years of age. Results: About ten parameters namely, perimeter and area of a triangle (formed by anterior ramus, coronion and mandibular notch) on the right and left side of mandible, and distances between anterior ramus and coronion, and between anterior ramus and mandibular notch and between coronion and mandibular notch (right and left sides of mandible) were analysed. By independent t-test, males were greater than females in all ten parameters $(p<0.01)$. Paired t-test between different sides of the coronoid process showed greater values on the right than left $(p<0.01)$. The discriminant function showed correct classification rate for $70 \%$ of cases, with identification accuracy of $75.8 \%$ for male and $63.1 \%$ for female. Conclusion: In brief, mandible is a sexually dimorphic bone useful for identification in forensic scenario. This is a pioneer study of the mandible in the Malaysians, which should be validated in future research.

\section{Keywords}

Coronoid process; Forensic; Identification; Mandible; Sex

\section{Introduction}

The knowledge of the anatomy of the mandible and its variations in relation to sex, age and race is essential for the physician, surgeon, medicolegal authorities, forensic anthropologist and scientist [1]. Mandible is the strongest and the largest bone in the human face [2]. It comprises several parts namely, arched body, two rami, two coronoid processes and two condylar processes [3]. In forensic practice, mandible plays a major role in the determination of sex, age and race in cases, where the intact skull is not found [4].

Of the methods, radiological method carries certain advantages over histological and biochemical methods [5]. The radiographic method is simple, quick, economic and non-invasive for identification of skeletal remains [6]. Advanced imaging modalities such as CT scan helps in image segmentation and avoids superimposition of anatomical structures [7].

In recent years, the use of advanced radiological technique especially CT scans in postmortem investigation had increased tremendously [8-12]. In many forensic organizations, CT has become a common diagnostic tool. Requests for the CT-based 
Citation: Alias A, Ibrahim ANM, Bakar SNA, Rokhani F, Shafie MS, et al. (2018) Morphometric Analysis of Coronoid Process of Mandible by CT in the Malaysian Population: An Important Step for Determination of Sex. J Dent Sci Res Ther 2018: 46-53. DOI: https://doi.org/10.29199/2637-7055/DSRT.101015.

method to determine sex from skeletal remains has risen in recent years. Thus, this study was performed to determine size variation of coronoid process in relation to sex in Malaysian adults. The results can be used for identification purposes by forensic anthropologists and scientists. Additionally, the coronoid process can be used for facial reconstruction purposes by the maxillofacial surgeon.

\section{Materials and Methods}

This research project was performed on 447 mandibles (894 different sides) from CT scan database in Malaysian adults retrieved from the Institut Perubatan Forensik Negara (IPFN), Hospital Kuala Lumpur and Department of Radiology, Universiti Kebangsaan Malaysia Medical Centre. This research was approved by the Research and Ethics committee Universiti Kebangsaan Malaysia (Ethics No: UKMPPM11/8/JEP-2016-359) and the Medical Research and Ethics Committee, Ministry of Health, Malaysia (Ethics No: NMRR-16-799-30027 (IIR). Subjects were divided into three ancestry groups i.e. Malay, Chinese and Indian, sex groups (male and female) and age groups i.e. (18-40), (41-60) and (51-87) years old. Damaged and edentulous mandibles were excluded from the study.

\section{Landmark Application}

A total of six bilateral 3D landmarks were designed (no,) and acquired using a Stratovan Checkpoint (v. 2017). The landmarks were chosen to correspond to those commonly used in the traditional metric and geometric morphometric systems, [13,14]. These landmarks were designed to characterize the shape of coronoid process of the mandible for complete descriptions and illustrations (Table 1; Figures 1 and 2).

Following landmark application, the coordinates of each landmark were exported to MorphoJ software via the Morphologica format. The raw data from MorphoJ was exported in excel form. In excel, ten parameters were measured on the right and left sides of the mandible (Table 2; Figures 3 and 4). Perimeter and areas of the triangle formed by anterior ramus, coronion and mandibular notch and distances between two landmarks were produced using the coordinates by different formula (Table 3 ).

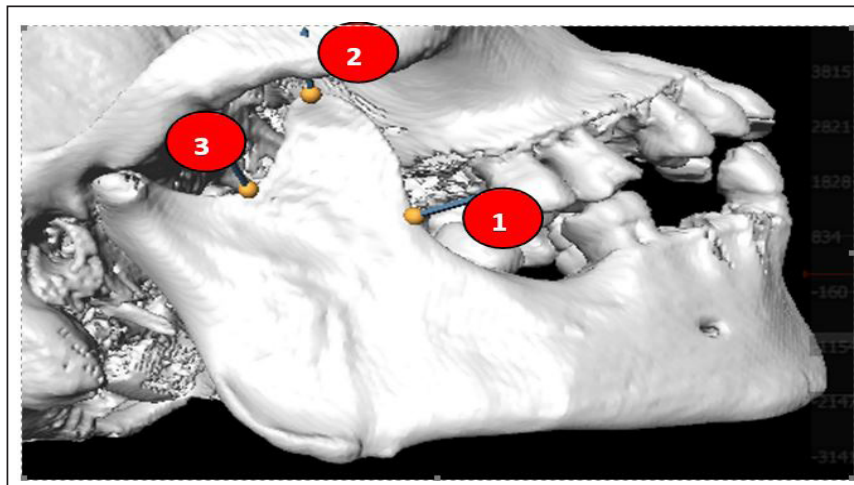

Figure 1: Landmarks on the right side of coronoid process (1-3).

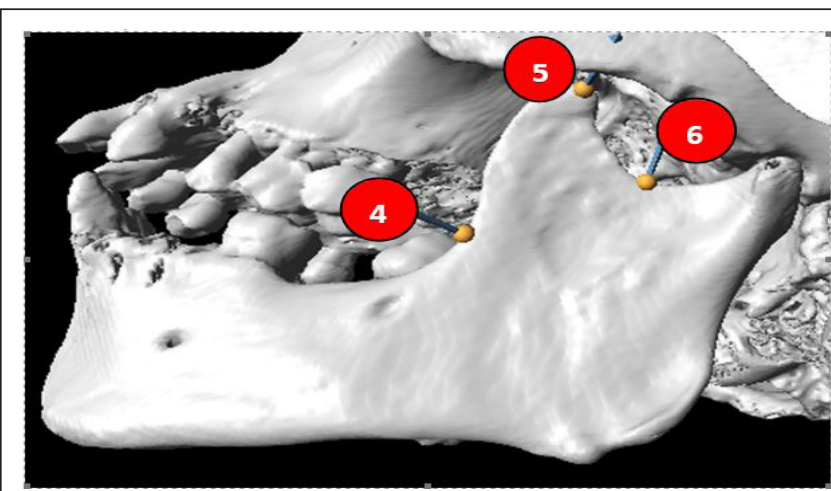

Figure 2: Landmarks on the left side of coronoid process (4-6).

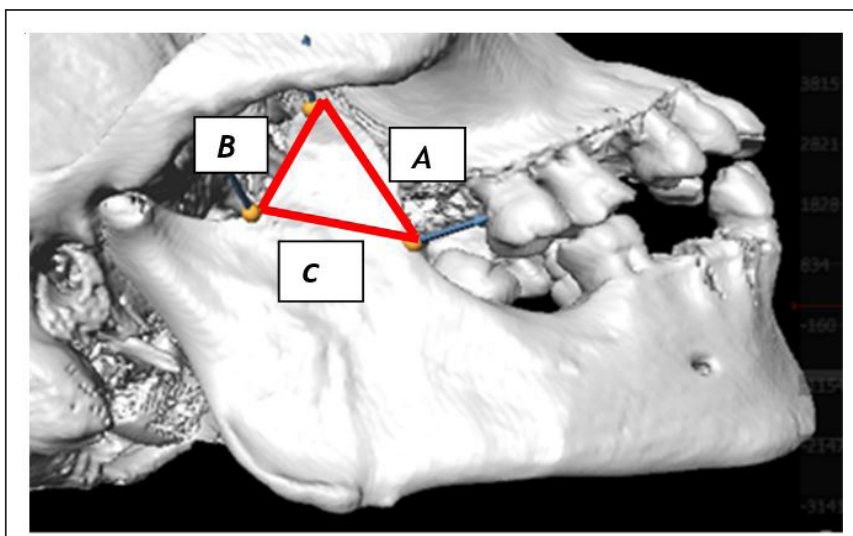

Figure 3: The border lines (A-C) formed on the right coronoid process.

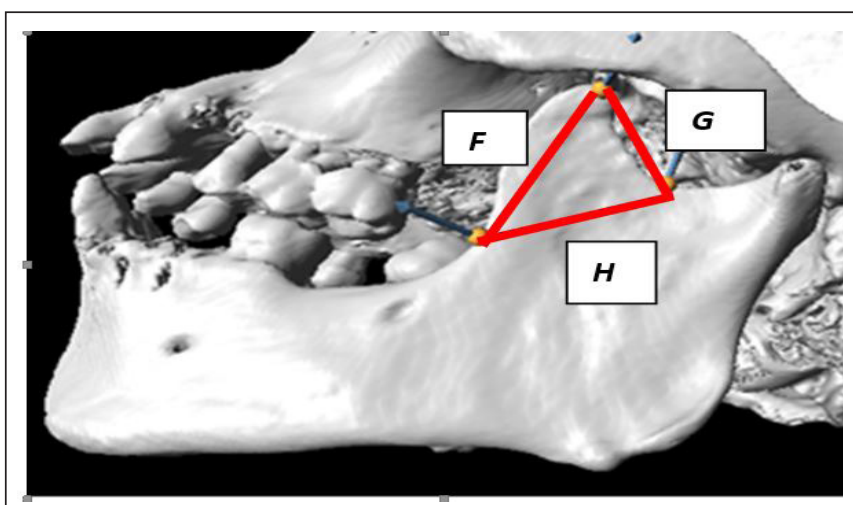

Figure 4: The border lines (F-H) formed on the left coronoid process

\section{Statistical Analysis}

The results were analyzed by SPSS (v. 21). Independent t-test was used to compare between male and female, paired t-test to compare between the left and the right side of the coronoid process and finally, discriminant functions were produced for male and female [15]. 
Citation: Alias A, Ibrahim ANM, Bakar SNA, Rokhani F, Shafie MS, et al. (2018) Morphometric Analysis of Coronoid Process of Mandible by CT in the Malaysian Population: An Important Step for Determination of Sex. J Dent Sci Res Ther 2018: 46-53.

\begin{tabular}{|l|l|l|}
\hline No & Landmark & Definition \\
\hline 1 & $\begin{array}{l}\text { Rt anterior } \\
\text { ramus }\end{array}$ & $\begin{array}{l}\text { The point at which the minimum } \\
\text { breadth transects the anterior } \\
\text { border of ramus }\end{array}$ \\
\hline 2 & Rt coronion & $\begin{array}{l}\text { The most superior point on the } \\
\text { coronoid process }\end{array}$ \\
\hline 3 & $\begin{array}{l}\text { Rt mandibular } \\
\text { notch }\end{array}$ & $\begin{array}{l}\text { The most inferior point on the } \\
\text { mandibular notch }\end{array}$ \\
\hline 4 & $\begin{array}{l}\text { ramus } \text { anterior } \\
\text { ramus point at which the minimum } \\
\text { breadth transects the anterior } \\
\text { border of ramus }\end{array}$ \\
\hline 6 & $\begin{array}{l}\text { Lt mandibular } \\
\text { notch }\end{array}$ & $\begin{array}{l}\text { The most superior point on the } \\
\text { coronoid process } \\
\text { mandibular notch }\end{array}$ \\
\hline
\end{tabular}

Table 1: Landmarks around the coronoid process and their descriptions.

\section{Results}

Results showed that male was significantly different in all ten parameters with male greater than female by independent t-test $(p<0.01)$ (Table 4). ). Paired t-test was done to compare between the right and left sides of coronoid process. There were significant differences in some of the parameters between the right and left side. The surface area and perimeter of left side were greater than right side, while the distance between coronion and mandibular notch of right side was greater than left side $(p<0.01)$ (Table 5).

The analysis was based on eight parameters $(p<0.01$; Wilk's $\lambda=$ $0.784 ; \chi^{2}=107.34 ; d f=8$ ) (Table 6), allowing a canonical discriminant function (D) to be employed (Table 6):

The discriminant functions showed correct classification rates for $70 \%$ of cases, with identification accuracy of $75.8 \%$ for male and $66.2 \%$ for female $(p<0.01)$. The discriminant function analysis was performed on the parameters derived from the right and left sides of coronoid process in males and females (Table 6). On cross-validation, the discriminant functions showed correct classification rates for $68 \%$, with identification accuracy of $74.6 \%$ for male and $60.1 \%$ for female (Table 8 ). A positive value indicated male, while a negative value indicated female.

\begin{tabular}{|c|c|c|c|}
\hline No. & Parameters & Landmark & Description \\
\hline 1. & A & $1-2$ & The distance between anterior ramus and coronion ( $R t$ side) \\
\hline 2. & $\mathrm{~B}$ & $2-3$ & $\begin{array}{r}\text { The distance between coronion and mandibular notch } \\
\text { (Rt side) }\end{array}$ \\
\hline 3. & $\mathrm{C}$ & $3-1$ & $\begin{array}{l}\text { The distance between mandibular notch and anterior ramus } \\
\text { (Rt side) }\end{array}$ \\
\hline 4. & $\mathrm{D}$ & $P$ & $\begin{array}{l}\text { The perimeter of a triangle formed by anterior ramus, coro- } \\
\text { nion and mandibular notch ( } R t \text { side })\end{array}$ \\
\hline 5. & $\mathrm{E}$ & $S A$ & Surface area of triangle $\mathrm{D}$ ( $R t$ side) \\
\hline 6. & $\mathrm{~F}$ & $4-5$ & Distance between anterior ramus and coronion ( $L t$ side) \\
\hline 7. & $G$ & $5-6$ & Distance between coronion and mandibular notch ( $L t$ side) \\
\hline 8. & $H$ & $6-4$ & $\begin{array}{l}\text { Distance between mandibular notch and anterior ramus ( } L t \\
\text { side) }\end{array}$ \\
\hline 9. & $I$ & $P$ & $\begin{array}{l}\text { The perimeter of a triangle formed by anterior ramus, coro- } \\
\text { nion and mandibular notch ( } L t \text { side) }\end{array}$ \\
\hline 10. & $J$ & $S A$ & Surface area of the triangle $I$ ( $L t$ side) \\
\hline
\end{tabular}

$S A$ - Surface area, $P$ - perimeter.

Table 2: The parameters of the coronoid process and descriptions. 
Citation: Alias A, Ibrahim ANM, Bakar SNA, Rokhani F, Shafie MS, et al. (2018) Morphometric Analysis of Coronoid Process of Mandible by CT in the Malaysian Population: An Important Step for Determination of Sex. J Dent Sci Res Ther 2018: 46-53. DOI: https://doi.org/10.29199/2637-7055/DSRT.101015.

\begin{tabular}{|c|c|c|c|}
\hline No. & Parameter & Landmark & Equation \\
\hline 1. & $\mathrm{~A}$ & $1-2$ & SQRT $(S U M X M Y 2(x 1+y 1+z 1, x 2+y 2+z 2))$ \\
\hline 2. & $\mathrm{~B}$ & $2-3$ & SQRT $(S U M X M Y 2(x 2+y 2+z 2, x 3+y 3+z 3))$ \\
\hline 3. & $\mathrm{C}$ & $3-1$ & SQRT $(S U M X M Y 2(x 3+y 3+z 3, x 1+y 1+z 1))$ \\
\hline 4. & $\mathrm{D}$ & $\mathrm{P}(R t)$ & $A+B+C$ \\
\hline 5. & $\mathrm{E}$ & $\mathrm{SA}(R t)$ & Heron Equation $=S Q R T(s(s-A)(s-B)(s-C))$ \\
\hline 6. & $\mathrm{~F}$ & $4-5$ & $S Q R T(S U M X M Y 2(x 4+y 4+z 4, x 5+y 5+z 5))$ \\
\hline 7. & $\mathrm{G}$ & $5-6$ & SQRT $(S U M X M Y 2(x 6+y 6+z 6, x 4+y 4+z 4))$ \\
\hline 8. & $\mathrm{H}$ & $6-4$ & $F+G+H$ \\
\hline 9. & $\mathrm{I}$ & $\mathrm{P}(L t)$ & Heron Equation $=S Q R T(s(s-F)(s-G)(s-H))$ \\
\hline 10. & $\mathrm{~J}$ & SA $(L t)$ & \\
\hline
\end{tabular}

$S A$ - Surface area, $P$ - perimeter.

Table 3: Equation produced based on the parameters on the coronoid process.

\begin{tabular}{|c|c|c|c|c|c|}
\hline Parameter & Description & Sex & Mean & SD & Sig. \\
\hline \multirow{2}{*}{ A } & \multirow{2}{*}{ Distance between anterior ramus and coronion ( $R t$ side) } & M & 2.83 & 0.38 & $0.01^{* *}$ \\
\hline & & $\mathrm{F}$ & 2.67 & 0.37 & $0.01^{* *}$ \\
\hline \multirow{2}{*}{ B } & \multirow{2}{*}{ Distance between coronion and mandibular notch ( $R t$ side) } & M & 2.13 & 0.23 & $0.01^{* *}$ \\
\hline & & $\mathrm{F}$ & 1.89 & 0.25 & $0.01^{* *}$ \\
\hline \multirow{2}{*}{$\mathrm{C}$} & \multirow{2}{*}{$\begin{array}{l}\text { Distance between mandibular notch and anterior ramus ( } R t \\
\text { side) }\end{array}$} & M & 2.33 & 0.25 & $0.01^{* *}$ \\
\hline & & $\mathrm{F}$ & 2.22 & 0.29 & $0.01^{* *}$ \\
\hline \multirow{2}{*}{$\mathrm{D}$} & \multirow{2}{*}{$\begin{array}{l}\text { Perimeter of a triangle formed by anterior ramus, coronion and } \\
\text { mandibular notch ( } R t \text { side) }\end{array}$} & M & 7.96 & 0.54 & $0.01^{* *}$ \\
\hline & & $\mathrm{F}$ & 7.57 & 0.57 & $0.01^{* *}$ \\
\hline \multirow{2}{*}{$\mathrm{E}$} & \multirow{2}{*}{ Surface area of triangle ' $\mathrm{D}$ '. } & M & 2.41 & 0.44 & $0.01^{* *}$ \\
\hline & & $\mathrm{F}$ & 2.07 & 0.47 & $0.01^{* *}$ \\
\hline \multirow{2}{*}{$\mathrm{F}$} & \multirow{2}{*}{ Distance between anterior ramus and coronion ( $L t$ side) } & $\mathrm{M}$ & 2.86 & 0.41 & $0.01^{* *}$ \\
\hline & & $\mathrm{F}$ & 2.66 & 0.36 & $0.01^{* *}$ \\
\hline \multirow{2}{*}{ G } & \multirow{2}{*}{ Distance between coronion and mandibular notch ( $L t$ side) } & $\mathrm{M}$ & 2.08 & 0.26 & $0.01^{* *}$ \\
\hline & & $\mathrm{F}$ & 1.86 & 0.25 & $0.01^{* *}$ \\
\hline \multirow{2}{*}{$\mathrm{H}$} & \multirow{2}{*}{$\begin{array}{l}\text { Distance between mandibular notch and anterior ramus ( } L t \\
\text { side) }\end{array}$} & $\mathrm{M}$ & 2.33 & 0.29 & $0.01^{* *}$ \\
\hline & & $\mathrm{F}$ & 2.21 & 0.29 & $0.01^{* *}$ \\
\hline \multirow[t]{2}{*}{ I } & \multirow{2}{*}{$\begin{array}{l}\text { Perimeter of a triangle formed by anterior ramus, coronion and } \\
\text { mandibular notch ( } L t \text { side })\end{array}$} & M & 7.27 & 0.82 & $0.01^{* *}$ \\
\hline & & $\mathrm{F}$ & 6.73 & 0.75 & $0.01^{* *}$ \\
\hline \multirow{2}{*}{$\mathrm{J}$} & \multirow{2}{*}{ Surface area of triangle ' $I$ '. } & $M$ & 2.38 & 0.49 & $0.01^{* *}$ \\
\hline & & $\mathrm{F}$ & 2.02 & 0.44 & $0.01^{* *}$ \\
\hline
\end{tabular}

\section{M- male, F- female, ${ }^{* *} \mathbf{p}<\mathbf{0 . 0 1}$}

Table 4: Independent $t$-test between male and female based on the parameters. 
Citation: Alias A, Ibrahim ANM, Bakar SNA, Rokhani F, Shafie MS, et al. (2018) Morphometric Analysis of Coronoid Process of Mandible by CT in the Malaysian Population: An Important Step for Determination of Sex. J Dent Sci Res Ther 2018: 46-53.

\begin{tabular}{|c|c|c|c|c|c|}
\hline Parameter & & Description & Mean & SD & Sig. \\
\hline \multirow{2}{*}{ Pair 1} & $\mathrm{~F}$ & $\begin{array}{l}\text { Distance between anterior ramus and coronion } \\
\text { (Lt side) }\end{array}$ & 2.77 & 0.40 & \multirow{2}{*}{0.49} \\
\hline & A & $\begin{array}{l}\text { Distance between anterior ramus and coronion } \\
(R t \text { side })\end{array}$ & 2.76 & 0.38 & \\
\hline \multirow{2}{*}{ Pair 2} & $\mathrm{~B}$ & $\begin{array}{c}\text { Distance between coronion and mandibular } \\
\text { notch }(R t \text { side })\end{array}$ & 2.02 & 0.27 & \multirow{2}{*}{$0.01^{* *}$} \\
\hline & G & $\begin{array}{c}\text { Distance between coronion and mandibular } \\
\text { notch }(L t \text { side })\end{array}$ & 1.98 & 0.28 & \\
\hline \multirow{2}{*}{ Pair 3} & $\mathrm{C}$ & $\begin{array}{c}\text { Distance between mandibular notch and anterior } \\
\text { ramus ( } R t \text { side })\end{array}$ & 2.28 & 0.28 & \multirow{2}{*}{0.67} \\
\hline & $\mathrm{H}$ & $\begin{array}{c}\text { Distance between mandibular notch and anterior } \\
\text { ramus ( } L t \text { side) }\end{array}$ & 2.27 & 0.29 & \\
\hline \multirow{2}{*}{ Pair 4} & $\mathrm{I}$ & $\begin{array}{l}\text { Perimeter of a triangle formed by anterior ramus, } \\
\text { coronion and mandibular notch ( } L t \text { side) }\end{array}$ & 7.78 & 0.59 & \multirow{2}{*}{$0.01^{* *}$} \\
\hline & $\mathrm{D}$ & $\begin{array}{l}\text { Perimeter of a triangle formed by anterior ramus, } \\
\text { coronion and mandibular notch (Rt side) }\end{array}$ & 7.03 & 0.83 & \\
\hline \multirow{2}{*}{ Pair 5} & $\mathrm{~J}$ & Surface area of triangle ' $I$ ' & 2.26 & 0.48 & \multirow{2}{*}{$0.01^{*}$} \\
\hline & $\mathrm{E}$ & Surface area of triangle ' $D$ ' & 2.21 & 0.50 & \\
\hline
\end{tabular}

$$
{ }^{* *} \mathrm{p}<0.01
$$

Table 5: Paired t-test between left and right side of coronoid process.

\begin{tabular}{|c|c|c|c|c|}
\hline Test of Function (s) & Wilks' Lambda & Chi- square & $\boldsymbol{d f}$ & Sig. \\
\hline 1 & 0.784 & 107.34 & 8 & 0.001 \\
\hline
\end{tabular}

$\mathrm{D}=-13.241-0.228(\mathrm{~A})+0.791(\mathrm{~B})+4.079(\mathrm{C})-4.58(\mathrm{D})-0.258(\mathrm{~F})-1.443(\mathrm{G})-1.5(\mathrm{H})+2.664(\mathrm{~J})$

Table 6: Summary of canonical discriminant functions.

\begin{tabular}{|c|c|}
\hline Parameters & Function \\
\hline $\mathrm{A}$ & -0.228 \\
\hline $\mathrm{B}$ & 7.906 \\
\hline $\mathrm{C}$ & 4.079 \\
\hline $\mathrm{E}$ & -4.58 \\
\hline $\mathrm{F}$ & -0.258 \\
\hline $\mathrm{G}$ & -1.443 \\
\hline $\mathrm{H}$ & -1.500 \\
\hline $\mathrm{J}$ & 2.664 \\
\hline (Constant) & -13.241 \\
\hline
\end{tabular}

Table 7: Unstandardised canonical discriminant function coefficients.

\begin{tabular}{|c|c|c|c|c|c|}
\hline & & & \multicolumn{2}{|c|}{$\begin{array}{l}\text { Predicted Group } \\
\text { Membership }\end{array}$} & \multirow[t]{2}{*}{ Total } \\
\hline & & & Male & Female & \\
\hline \multirow{4}{*}{ Original } & \multirow{2}{*}{ Count } & Male & 185 & 59 & 244 \\
\hline & & Female & 75 & 128 & 203 \\
\hline & \multirow{2}{*}{$\%$} & Male & 75.8 & 24.2 & 100.0 \\
\hline & & Female & 36.9 & 63.1 & 100.0 \\
\hline \multirow{4}{*}{$\begin{array}{c}\text { Cross- } \\
\text { validated }\end{array}$} & \multirow{2}{*}{ Count } & Male & 182 & 62 & 244 \\
\hline & & Female & 81 & 122 & 203 \\
\hline & \multirow{2}{*}{$\%$} & Male & 74.6 & 25.4 & 100.0 \\
\hline & & Female & 39.9 & 60.1 & 100.0 \\
\hline
\end{tabular}

Table 8: Classification rate for male and female coronoid process. 
Citation: Alias A, Ibrahim ANM, Bakar SNA, Rokhani F, Shafie MS, et al. (2018) Morphometric Analysis of Coronoid Process of Mandible by CT in the Malaysian Population: An Important Step for Determination of Sex. J Dent Sci Res Ther 2018: 46-53. DOI: https://doi.org/10.29199/2637-7055/DSRT.101015.

\section{Discussion}

Sex determination is the most important step for developing biological profile during the examination of skeletalized remains [16]. The skull is the second most sexually dimorphic bone after pelvis, which showed variation in size and morphology between different sexes [18]. Several studies has been done on long bones, ribs [19], vertebrae [20], clavicle [21], sternum [22], mandible [16], femur [23], radius [24], calcaneum [13], mastoid process [25], humerus [26] and ilium [27] for sexual dimorphism. Each study provides discriminant functions for determination of sex based on metric characteristics of the bones. The anatomical position and its functions vary between sexes. Thus, some bones may show significant difference more physically than others [28]. Forensic anthropologists across the world studied population-specific variation among different populations and have found differences in their physical attributes [16].

In this study, coronoid process of mandible was selected as one of the few parts in mandible. This study showed that all parameters showed significant difference between males and females, with males showing greater values than females. The difference between sexes is believed to be due to hormonal changes and rate of growth, which are different in both sexes [29]. Male usually exhibits adult characteristics after puberty, while female maintains pedomorphic features after puberty [30]. Males are taller, have robust cranial and facial features as well as greater muscularity than females [31].

The use of muscles during mastication contributes to different shapes of mandibles, as they are attached to different parts of the mandible. In a study, the coronoid process of mandible was reduced after removal or denervation of temporalis muscle in rats [32]. However, in masseter hypertrophy, the angle of mandible became enlarged [33]. This region can be considered as the most sexually dimorphic part due to its presence of muscles of mastication. Male has greater and stronger musculature than female, which produced greater forces leading to larger mandible and rougher surfaces due to greater muscle attachments [33-35]. Mandibles in this study generally showed pronounced degree of sexually dimorphic features for all landmarks. There was no integrated time trend in the pattern of sexual dimorphism in mandible across populations, but there were several population-specific features, which were sexually dimorphic. Thus, the mandible may be used as an anthropological tool to determine biological identification of an individual.

The sexually dimorphic features of the mandible can be accurately determined after puberty as mandibular development, growth rates and duration of growth may be different in both sexes [36]. As endocrine stimulation is fully developed during puberty, mandibular growth becomes stable around 14 years of age in female and 16 years in males. The muscular shape and size of mandible are well developed during puberty. The male typically has a larger mandible with rougher surface, while female has smaller mandible with smoother surface. The weaker forces used by female during mastication contribute to smaller mandible and smoother surfaces than that in male.

The different amount of forces and stresses in bones during locomotion in male and female gives an added effect to sexual dimorphic features of bone. An active person, who always moves about may exhibit robust bones when compared to those, who are sedentary. Therefore, the role of sex and sociocultural factors may affect sexual dimorphism of a bone. The secular changes in modern populations indicated that onset of puberty occurred earlier due to changes in diet and nutrition. The skeletal development and maturity in humans improve quickly due to modern populations having more access to food and health care. Environmental factors such as food, oxygen and muscle function may produce associated strain pattern in bones [37].

Environmental factors such as diet, masticatory stress, medical care, dental health care, urbanization and population growth, as well as childhood mortality and adult longevity influence mandibular size and shape. The cultural influence in facial characteristics for attraction also played a major role. The sexual dimorphic features in mandible are more pronounced in the higher socioeconomic group. The degree, pattern and accuracy rate of sexual dimorphism in mandibles vary with population. There were previous studies that showed craniofacial changes in population with different dietary pattern [38-40]. The morphology and size of mandible in the population may be affected by environmental factors, thus contributing to its variation. Previous studies that focused on hunter-gatherers and farmers proved that hunter gatherers typically have larger and robust skulls due to its origin of agriculture and technological advance in preparing food $[36,41]$.

In this study, there was a significant difference between the right and left coronoid process, however previous symmetrical study had shown that there was no difference between the right and left side coronoid process in different sexes [42]. The classification accuracy in this study was $70 \%$ for coronoid process of mandible. The results were comparable with the literature in the other populations. For instance, Hanihara (1959) used four variables on mandible, and found $85 \%$ accuracy in Japanese mandible [43]. A study on eight mandibular measurements in the American whites and Blacks showed $84 \%$ accuracy rate between different sexes [44]. By using mandible in the South Africans White, there was $81.5 \%$ accuracy rate in sex determination [45].

\section{Conclusion}

In conclusion, the coronoid process may exist in several different morphological shapes and sizes, which may be influenced by various socio-demographic factors affecting directly or indirectly contributing to its final appearance. This study will thus, enhance human identification by identification of the coronoid process. The research may be useful for validation and comparison with other population studies. 
Citation: Alias A, Ibrahim ANM, Bakar SNA, Rokhani F, Shafie MS, et al. (2018) Morphometric Analysis of Coronoid Process of Mandible by CT in the Malaysian Population: An Important Step for Determination of Sex. J Dent Sci Res Ther 2018: 46-53.

\section{Conflict of Interest}

We disclose that there is no conflict of interest in the writing of the manuscript.

\section{Acknowledgement}

Special thanks to Dr Nurliza Abdullah and Dr Mohamad Helmee Mohamad Noor from IPFN and Dr Fazalina Mohd Fadzilah from the Department of Radiology, UKM Medical Centre for having access to the database. The authors acknowledged the technical help from Prof Dr Srijit Das, who edited the manuscript. Appreciation goes to UKM for funding this eminent research project (Project Code No: GGPM-2016-069 and UKMFPR.4/244/FF2016-235).

\section{References}

1. Tapas S (2014) Morphological variations of coronoid process in dry adult human mandibles. Int J Appl Basic Med Res 3: 401-405.

2. Standring S (2011) Gray's Anatomical Basis of Clinical Practice. Reprinted International (40 ed). Chapter - Mandible. Churchill. Livingstone, Elsevier, London (UK).

3. Harrison RJ (1981) Cunningham's textbook of anatomy. Reprinted (12 ed.) Chapter bones - The mandible. Oxford University Press, UK pp: 127.

4. Saini V, Srivastava R, Rai RK, Shamal SN, Singh TB, et al. (2011) Mandibular ramus: an indicator for sex in fragmentary mandible. $\mathrm{J}$ Forensic Sci 56: S13-16.

5. Vandevoort F, Bergmans L, Cleynenbreugel J, Bielen D, Lambrechts $\mathrm{P}$, et al. (2004) Age calculation using $\mathrm{x}$-ray microfocus computed tomographical scanning of teeth: A pilot study. J Forensic Dent Sci 49: 789-790

6. Babar MG, Iqbal S, Jan A (2008) Essential guidelines for forensic dentistry. Pakistan Oral Dent J 27: 79-84.

7. Saxena S (2011) Age estimation of Indian adults from orthopantomographs. Brazilian Oral Res 25: 225-229.

8. Leth PM (2009) Computerized tomography used as a routine procedure at postmortem investigations. Am J Forensic Med Pathol 30: 219-222.

9. Thali MJ, Braun M, Wirth J, Vock P, Dirnhofer R (2003) 3D surface and body documentation in forensic medicine: 3-D/CAD photogrammetry merged with $3 \mathrm{D}$ radiological scanning. J Forensic Sci 48: 1356-1365.

10. Thomsen AH, Jurik AG, Uhrenholt L, Vesterby A (2009) An alternative approach to computerized tomography (CT) in forensic pathology. Forensic Sci Int 183: 87-90.

11. Thali MJ, Yen K, Schweitzer W, Vock P, Boesch C, et al. (2003) Virtopsy, a new imaging horizon in forensic pathology: virtual autopsy by postmortem multislice computed tomography (MSCT) and magnetic resonance imaging (MRI) - a feasibility study. J Forensic Sci 48: 386-403.

12. Dirnhofer R, Jackowski C, Vock P, Potter K, Thali MJ (2006) VIRTOPSY: minimally invasive, imaging-guided virtual autopsy. Radiographics 26: 1305-1333.
13. Franklin D, Cardini A, Higgins PO, Oxnard CE, Dadour I (2008) Mandibular morphology as an indicator of human subadult age: geometric morphometric approaches. J Forensic Sci 91-99.

14. Harvati K, Morphometrics TG, Nicholson E, Harvati K (2017) Quantitative analysis of human mandibular shape using three-dimensional geometric morphometrics Quantitative Analysis of Human Mandibular Shape Using. Am J Phys Anthropol 131: 368-383.

15. "SPSS (IBM Corp. Released 2013. IBM SPSS Statistics for Windows, Version 21.0. Armonk, NY: IBM Corp.)

16. Franklin D, Higgins PO, Oxnard CE, Dadour I (2007) Sexual dimorphism and population variation in the adult mandible forensic applications of geometric morphometrics. Forensic Sci Med Pathol 3: $15-22$.

17. Pregarz M, Fugazzola C, Consolo U, Andreis IA, Beltramello A, et al. (1998) Computed tomography and magnetic resonance imaging in the management of coronoid process hyperplasia: review of five cases. Dentomaxillofac Radiol 27: 215-220.

18. Rezić A, Bošković I, Lubinu P, Piria M (2017) Dimorphism in the skull form of golden jackals balkans: a geometric morphometric approach. Pakistan J Zool 49(3): 989-997.

19. Note T (2017) Sexual Dimorphism of the First Rib: A Comparative Approach Using Metric and Geometric Morphometric Analyses. J Forensic Sci 62: 1251-1258.

20. Chen L, Lin J, Xu T, Long X (2009) The longitudinal sagittal growth changes of maxilla and mandible according to quantitative cervical vertebral maturation. J Huazhong Univ Sci Technolog Med Sci 29: 251-256.

21. Zhong SC, Xu ZJ, Zhang ZG, Zheng YH, Li TX, et al. (2009) Bilateral coronoid hyperplasia (Jacob disease on right and elongation on left): report of a case and literature review. Oral Surg Oral Med Oral Pathol Oral Radiol Endod 107: e64-67.

22. Zhang K, Luo Y, Fan F, Zheng J, Yang M, et al. (2015) Stature estimation from sternum length using computed tomography-volume rendering technique images of western Chinese. J Forensic Leg Med 35: 40-44.

23. Cavaignac E, Li K, Faruch M, Savall F, Chiron P, et al. (2017) Three-dimensional geometric morphometric analysis reveals ethnic dimorphism in the shape of the femur. J Exp Orthop, 4: 13.

24. Timme M, Ottow C, Schulz R, Pfeiffer H, Heindel W, et al. (2016) Magnetic resonance imaging of the distal radial epiphysis: a new criterion of maturity for determining whether the age of 18 has been completed? Int J Leg Med 131: 579.

25. Anja P, Sabrina B, Sholts M, Slaus A, Bosnar A, et al. (2015) Evaluating Sexual Dimorphism in the HumanMastoid Process:A Viewpoint on the Methodology. Clin Anat 28: 593-601.

26. Kranioti EF, Bastir M, Sánchez-Meseguer A, Rosas A (2009). A geometric-morphometric study of the cretan humerus for sex identification. Forensic Sci Int 189: e1-8.

27. Bilfeld MF, Dedouit F, Sans N, Rousseau H, Rougé D (2013). Ontogeny of Size and Shape Sexual Dimorphism in the llium: A Multislice Computed Tomography Study by Geometric Morphometry. J Forensic Sci 58: 303-310.

28. Biwasaka H, Aoki Y, Sato K, Tanijiri T, Fujita S, et al. (2012) Analyses of sexual dimorphism of reconstructed pelvic computed tomography images of contemporary Japanese using curvature of the greater sciatic notch, pubic arch and greater pelvis. Forensic Sci Int 219: 
Citation: Alias A, Ibrahim ANM, Bakar SNA, Rokhani F, Shafie MS, et al. (2018) Morphometric Analysis of Coronoid Process of Mandible by CT in the Malaysian Population: An Important Step for Determination of Sex. J Dent Sci Res Ther 2018: 46-53. DOI: https://doi.org/10.29199/2637-7055/DSRT.101015.

\section{8.e1-8}

29. Fink B, Grammer K, Mitteroecker P, Gunz P, Schaefer K, et al (2005) Second to fourth digit ratio and face shape. Proceedings of the Royal Society of London.

30. Wood, C. (2015). The age-related emergence of cranial morphological variation. Forensic Sci Int 251: 220.e1-220.e20.

31. Roma A, Manzi G, Saracino B, Bruner E, Passarello P, et al. (2000) Geometric morphometric analysis of mid-sagittal cranial profiles in Neandertals, modern humans, and their ancestors. Rivista di Antropologia 78: 193-204.

32. Nayak S, Patra S, Singh G, Mohapatra C, Rath S (2015) Study of the Size of the Coronoid Process of Mandible. IOSR J Dental Medic Sci 14: 2279-861.

33. Larrazabal-Moron C, Sanchis-Gimeno JA (2018) Gonial angle growth patterns according to age and gender. Ann Anat 215: 93-96.

34. Vodanović M, Demo Ž, Njemirovskij V, Keros J, Brkić H (2007) Odontometrics: a useful method for sex determination in an archaeological skeletal population? J Archaeol Sci 34: 905-913.

35. Chovalopoulou ME, Valakos ED, Manolis SK (2016) Sex determination by three-dimensional geometric morphometrics of the vault and midsagittal curve of the neurocranium in a modern Greek population sample. Homo 67: 173-187.

36. Dadour I (2007) Sexual dimorphism in the subadult mandible: Quantification Using Geometric Morphometrics. J Forensic Sci 52: 6-10.

37. Ross AH, Ubelaker DH, Kimmerle EH (2011) Implications of dimor- phism, population variation, and secular change in estimating population affinity in the Iberian Peninsula. Forensic Sci Int 206: 214. e1-5.

38. Gonza lez-Jose R, Ramirez-Rozzi F, Sardi M, Martınez-Abadıas $\mathrm{N}$, Hernandez M, et al. (2005) Functional-cranial approach to the influence of economic strategy on skull morphology. Am J Phys Anthropol 128: 757-771.

39. Sardi ML, Novellino PS, Pucciarelli HM (2006) Craniofacial morphology in the Argentine Center-West: consequences of the transition to food production. Am J Phys Anthropol 130: 333-334.

40. Pinhasi R, Eshed V, Shaw P (2008) Evolutionary changes in the masticatory complex following the transition to farming in the Southern Levant. Am J Phys Anthropol 135: 136-148.

41. Brace CL, Smith SL, Hunt KD (1991) What big teeth you had grandma! Human tooth size, past and present. In: Kelley MA, Larsen CS. Advances in dental anthropology. Wiley-Liss, New York p: 33-57.

42. Derek A Sanders (2014) "Quantification of skeletal asymmetries in normal adolescents: cone-beam computed tomography analysis". Progress in Orthodontics 15: 26.

43. Hanihara K (1959) Sex diagnosis of Japanese skulls and scapulae by means of discriminant functions. J Anthropol Soc Nippon 67:1917.

44. Giles E (1964) Sex determination by discriminant function analysis of the mandible. Am J Phys Anthropol 22: 129-135.

45. Steyn M, Işcan MY (1998) Sexual dimorphism in the crania and mandibles of South African whites. Forensic Sci Int 98: 9-16. 